\title{
A Pilot Study on the Use of Botulinum Toxin in Spasmodic Torticollis
}

\author{
J.K. Tsui, A. Eisen, E. Mak, J. Carruthers, A. Scott and D.B. Calne
}

\begin{abstract}
Dystonic torticollis has been treated with local injections of botulinum toxin in a single blind study of 12 patients. A significant decrease of abnormal movements was recorded, and pain improved. Further studies are desirable to define the optimum dosage and site for injections, and the long term effects of repeated injections.
\end{abstract}

RÉSUMÉ: Une étude pilote sur l'emploi de la toxine botulinique contre le torticolis spasmodique Le torticolis dystonique fut traité chez 9 patients, lors d'une étude à simple insu, par l'injection locale de toxine botulinique. Une diminution significative des mouvements anormaux fut notée, avec une amélioration de la douleur. D'autres études seront nécessaires pour définir la dose optimale et le site d'injection et pour préciser les effets à long terme d'injections répétées.

Can. J. Neurol. Sci. 1985; 12:314-316

Spasmodic torticollis is a dystonic disorder characterized by abnormal muscle activity and abnormal posturing of the head and neck. This may be tonic, paroxysmal, or both. A detailed analysis of the different types of neck muscle activities in spasmodic torticollis had been described by Podivinsky (1968). The etiology is not known, although pathology in the neostriatum has been suggested in several necropsy studies (Alpers et al 1937, Foerster 1933, Grinker et al 1933) and the condition may be associated with, or develop into, generalized dystonia and tremor (Couch 1976, Marsden et al 1974, Matthews et al 1978).

A variety of medications have been tried without consistent or satisfactory results. These have included various anticholinergic, dopaminergic, serotonergic, and GABAergic agents, as reviewed by Lal (1979). Alternatively treatment has been directed to the peripheral nervous system (motor nerve roots, nerves, neuromuscular junctions or muscles). Various surgical procedures, including section of the sternomastoid, section of the accessory nerve, and selective cervical rhizotomy have been tried with limited benefit.

We report our preliminary experience with chemical denervation induced by botulinum toxin in 12 patients with spasmodic torticollis.

\section{METHODS}

\section{Patients}

Twelve patients ( 11 women, 1 man) of mean age 48.8 years ( \pm 11.4 S.D.) with torticollis were demonstrated to be resistent to conventional medical therapy. Current medications were not changed. Mean age of onset of symptoms was 41.9 years \pm 12.9. There was no family history of dystonia. One patient had associated blepharospasm and oromandibular dystonia, which had previously been treated with injections of botulinum toxin with good results.

\section{Clinical Evaluation}

A semiquantitative scale based on the amplitude and duration of abnormal movement was employed in nine patients as outlined below:

(A) Amplitude of sustained movements:

1. Rotation $0=$ absent $1=<15^{\circ} \quad 2=15-30^{\circ}$ $3=>30^{\circ}$

2. Lateral head tilt $0=$ absent $1=$ mild $2=$ moderate $3=$ severe

3. Shoulder-elevation/depression $0=$ absent $1=$ mild $2=$ severe

Total $=\mathrm{A}$

(B) Duration of sustained movements:

$1=$ intermittent $2=$ constant

Total $=$ B

(C) Unsustained head movements (head tremor/jerk):

(severity) $1=$ mild 2 = severe (i)

(duration) $1=$ occasional $2=$ continuous (ii)

Total $=$ (i) $\times$ (ii) $=\mathrm{C}$

The severity of the torticollis was expressed as the product of the amplitude multiplied by the duration of the abnormal movements. The degree of head tremor or jerk was similarly obtained by multiplying the corresponding extent and duration. The final score, being the sum of the above. was calculated by substituting the values into the following formula:

$$
\text { Final score }=[(\mathrm{A}) \times(\mathrm{B})]+(\mathrm{C}) \text {. }
$$

From the Division of Neurology, University of British Columbia, Health Science Centre Hospital, Vancouver (Drs. Tsui, Eisen, Mak and Calne); the Department of Ophthalmology, University of British Columbia, (Dr. Carruthers) and the Smith Kettlewell Foundation, San Francisco, California (Dr. Scott)

Reprint requests to: Dr. D. Calne, Division of Neurology, Health Sciences Centre Hospital, 2211 Westbrook Mall, University of British Columbia, Vancouver, British Columbia, Canada V6T IW5 
The patients were recorded on videotape immediately before and six months after the start of each series of multiple injections. The recordings were arranged in two different random orders and the entire series of pictures were evaluated by a physician unaware of which recordings were made before or after treatment.

\section{Botulinum toxin}

Injections were given into the muscles which were most active on clinical observation and palpation. These corresponded well with the patients' description of the sites where they felt the worst pull on the neck. The precise site of injection in individual muscles was at first determined by EMG guidance; the points which had the lowest threshold of response to electrical stimulation were taken as the sites closest to the motor end-plates. Subsequently it was found out that the effects were not enhanced by this preliminary maneuvre, so it was abandoned. A total dose of 25 mouse units (equivalent to $10 \mathrm{ng}$ ) of botulinum toxin diluted with saline into $0.25 \mathrm{ml}$ was injected into each of not more than two muscles at any one session. If more muscles had to be injected, this was undertaken one week later. The total dose of botulinum toxin injected at a single session never exceeded 50 units $(20 \mathrm{ng}$ ). The muscles most frequently injected were the sternomastoids contralateral to the direction of rotation, and the ipsilateral trapezii. We also injected the splenii where indicated.

Patients were seen again six weeks and three months after the injections. They were followed by telephone in the first two weeks and reported any symptoms they thought might be related to the injections. They were all asked specifically about the occurrence of local or generalized weakness.

Subjective improvement usually occurred three to five days after the injections. This improvement lasted for four to eight weeks, by which time the effects had generally disappeared. All patients required reinjection at the end of three months. All patients were reassessed at the end of six months.

In three patients involuntary sternomastoid activity was assessed clinically, "unblind", following 25 units (1 patient) and 50 units ( 3 patients).

\section{Results}

\section{Efficacy}

After six months of therapy, all patients except one experienced subjective improvement of their torticollis. The most marked benefit was the relief of pain in all six patients who had severe neck pain due to muscle spasm.
The sets of duplicate scores were compared by the MannWhitney rank-sum test and they were not significantly different showing little observer variation in scoring. The mean of the two scores and after treatment are summarized in Table 1 . Using the Wilcoxon signed-rank test, there was a significant $(p<.01)$ fall in the torticollis scores after treatment.

The results of the "unblinded" observations are shown in Figure 1.

Subjective improvement was reported in eleven out of twelve patients and this corresponded well to the scored results. The only exception was one case who felt subjective improvement was up to $60 \%$ whereas the score after treatment was the same as the score before.

\section{Toxicity}

The injections were well tolerated. Two patients reported shooting pain up the back of the neck at the injection sites lasting for one to two days. Neck weakness was reported in three patients. This was mild in two and only noticeable on heavy exertion. In one patient there was slight difficulty lifting the head off the pillow. All neck weakness was transient and lasted for a maximum of three days. Four patients experienced lassitude for two to three days after the injections. This was a minor symptom and did not impair their daily routines. One patient felt sleepy for one day after the injection.

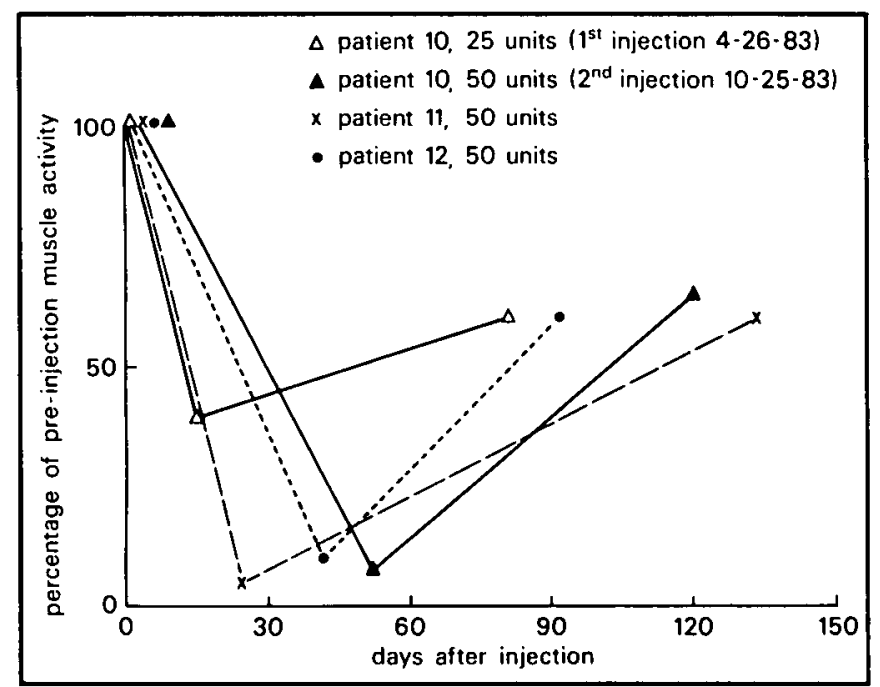

Figure I - "Unblinded" assessment of involuntary activity in sternomastoid muscles in 3 patients.

Table 1: Quantitative scoring for severity of torticollis in 9 patients before and after treatment with botulinum toxin

\begin{tabular}{|c|c|c|c|c|c|c|c|c|c|c|}
\hline 1. & $100 \mathrm{u}$ & 6,7 & 2,2 & 0,0 & 13 & 2,1 & 1,0 & 0,0 & 1 & 12 \\
\hline 3. & $100 \mathrm{u}$ & 2,4 & 2,2 & 2,4 & 9 & -1 &,- 1 & -1 & 2 & 7 \\
\hline 4. & $100 u$ & 7,6 & 2,2 & 0,0 & 13 & 0,0 & 0,0 & 1,1 & 1 & 12 \\
\hline 5. & $100 \mathrm{u}$ & 5,6 & 2,2 & 2,2 & 13 & 7,6 & 2,2 & 0,0 & 13 & 0 \\
\hline 8. & $150 \mathrm{u}$ & 6,7 & 2,2 & 0,0 & 13 & 6,5 & 2,1 & 0,0 & 8.5 & 4.5 \\
\hline 9. & $100 \mathrm{u}$ & 3,3 & 2,2 & 2,2 & 8 &,- 1 &,- 1 &,- 1 & 2 & 6 \\
\hline
\end{tabular}

* $p<.01$ for difference in scores as a group. 


\section{DISCUSSION}

This pilot study has demonstrated that botulinum toxin provides temporary benefit in the treatment of torticollis and that the toxin can be injected focally in small doses without serious adverse effects. Transient local neck weakness or general lassitude may occur but these symptoms are mild and transient. It is likely that patients will need to be reinjected every two to three months.

Chemical denervation of neck muscles was introduced by Schaltenbrand (1938). Schwind and Schulz (1960) reported satisfactory results in four patients with injections of novocaine and quinine into the sternomastoids and the splenii. However, no long term follow up of these patients was reported.

Botulinum toxin is an exotoxin produced by Clostridium botulinum. It impairs the release of acetylcholine from nerve endings at the neuromuscular junctions and produces muscle weakness or paralysis. The lethal dose for $50 \%$ in human subjects, extrapolated from experiments in monkeys (Scott et al 1973), is 1 microgram. A very small dose injected into single muscles in human subject produces temporary weakness. The use of botulinum toxin in human subjects was pioneered by Scott (1980). It has been used in the treatment of blepharospasm with good results, which have been confirmed (Frueh et al 1984). There were no serious side effects in treating blepharospasm and the injections could be performed on outpatients. The paresis lasted for only 2-3 months, after which reinjections were necessary.

The dosage for the treatment of blepharospasm has been 2.5 ng per eyelid (Frueh et al 1984). A larger dose of $10 \mathrm{ng}$ was used in this study for each muscle injected, and this produced sufficient weakness to relieve pain and torticollis for periods lasting up to three months. Further studies are desirable to establish the optimum regimen for injections defining dosage, site, and timing. Long term follow-up observations are also needed.

Electromyographic (EMG) evidence of denervation has been described in the injected muscle in blepharospasm 24 hours after administration of botulinum toxin, and subsequent EMG changes in the frontalis muscle were found after 48 hours. Spread to more distant arm muscles has been claimed after 6-8 weeks (Sanders et al 1985). In the present study, three patients noted neck weakness which developed 24-48 hours after the injections, and lasted for a maximum of three days. This probably resulted from the action of the toxin in the injected and neighbouring neck muscles. The generalized tiredness reported by three patients also suggested a distant effect on other muscles of the body; the onset was again 24-48 hours after the injection and the duration was up to three days. Such findings conflict with the timing of EMG changes described by Sanders (1985), so further EMG studies are desirable to clarify this discrepancy.

\section{ACKNOWLEDGEMENTS}

This work was supported by the Dystonia Medical Research Foundation and the Medical Research Council of Canada. We thank Dr. M. Schulzer for his statistical advice and Susan Calne R.N. for her contribution in this project.

\section{REFERENCES}

Alpers BJ, Drayer CS (1937) The organic background of some cases of spasmodic torticollis. Am J Med Sci 193: 378-384.

Couch JR (1976) Dystonia and tremor in spasmodic torticollis. Advances in Neurology Vol 14 edited by Eldridge and Fahn, Raven Press, N.Y.

Foerster $O$ (1933) Mobile spasm of the neck muscles and its pathological basis. J Comp Neurol 58: 725-735.

Frueh BR, Felt DP, Wojno TH, Musch DC (1984) Treatment of blepharospasm with botulinum toxin. Arch Ophthalmol 102: 1464-1468.

Grinker RR, Walker AC (1933) The pathology of spasmodic torticollis with a note on respiratory failure from anaesthesia in chronic encephalitis. J Nerv Ment Dis 78: 430-437.

Hassler R, Dieckmann G (1970) Stereotactic treatment of different kinds of spasmodic torticollis. Confin Neurol 32: 135-143.

Lal S. (1979) Pathophysiology and pharmacotherapy of spasmodic torticollis: a review. Can J Sci Neurol 6: 427-435.

Marsden CD, Harrison MJG (1974) Idiopathic torsion dystonia (Dystonia musculorum deformans), a review of forty-two patients. Brain 97 : 793-810.

Matthews WB, Beasley P, Parry-Jones W, Garland G (1978) Spasmodic torticollis: a combined clinical study. J Neurol Neurosurg Psychiat 41: 485-492.

Meares R (1971) Natural history of spasmodic torticollis, and effect of surgery. Lancet 2: 149-151.

Podivinsky F (1968) Torticollis. In: Handbook of Clinical Neurology, Vol 6, edited by Vinken and Bruyn, North-Holland, Amsterdam. 567-603.

Sanders DB, Massey EW, Buckley EC (1985) EMG monitoring of botulinum toxin in blepharospasm. Neurology 35 (Supp 1): 272.

Schaltenbrand G(1938) Klinik und behandlung des Torticollis spasticus. Dtsch Z Nervenheilk 145: 36-53.

Schwind VF, Schutz E (1960) Beitrag zur konservativen Behandlung des Torticollis spasticus. Der Nervenartz 31: 318-319.

Scott AB, Rosenbaum, AL, Collins, CC (1973) Pharmacologic weakening of extraocular muscles. Invest Ophthalmol 12: 924-927.

Scott AB (1980) Botulinum toxin injection into extraocular muscles as an alternative to stabismus surgery. Ophthalmology 87: 1044-1047. 